\title{
Synthesis of $\mathrm{SnO}_{2}$ Hollow Microspheres with Efficient Photocatalytic Activity for Tetracycline Hydrochloride
}

\author{
Huancong Shi ${ }^{1, *}$, Qiming $W u^{1}$, linhua Jiang ${ }^{1, *}$, Lin Wang $^{3}$, Min Huang ${ }^{1}$, Bing Han ${ }^{1}$, \\ Zhihao Yu ${ }^{1}$, Yuanhui Zuo ${ }^{2, *}$ \\ ${ }^{1}$ Department of Environment Science and Engineering, Shanghai Key lab of Modern Optical Systems, \\ The Public Experiment Center, University of Shanghai for Science and Technology, Shanghai 200093, \\ China \\ ${ }^{2}$ College of Environmental Science and Engineering, Tongji University, Shanghai 200092, China \\ ${ }^{3}$ Zhejiang Alljoin Law Firm, Ningbo, Zhejiang, 315000, China. \\ *E-mail: hcshi@usst.edu.cn, hhjiang@usst.edu.cn, zyh06101@163.com
}

doi: $10.20964 / 2020.02 .41$

Received: 12 October 2019 / Accepted: 8 December 2019 / Published: 31 December 2019

\begin{abstract}
Antibiotic residues lead to serious environment pollution and provoke many health problems. Among all the antibiotics, Tetracycline hydrochloride (TC- $\mathrm{HCl})$ in surface and drinking waters around the world has attracted widespread attention. Large-scale $\mathrm{SnO}_{2}$ with hollow microspheres were synthesized via one-step hydrothermal approach as a high-efficiency photocatalyst to degrade TC-HCl. These synthesized series of $\mathrm{SnO}_{2}$ materials with various molar ratios were characterized by XRD, SEM and EIS in terms of crystal structure, morphology, and electronic resistance. $\mathrm{SnO}_{2}$ hollow microspheres synthesized with $\mathrm{SnCl}_{2} \cdot 2 \mathrm{H}_{2} \mathrm{O}$ to $\mathrm{Na}_{3} \mathrm{C}_{6} \mathrm{H}_{5} \mathrm{O}_{7} \cdot 2 \mathrm{H}_{2} \mathrm{O}$ at the molar ratio of $1: 4$ showed the best photocatalytic degradation activity of $\mathrm{TC}-\mathrm{HCl}$ under UV light illumination. The high photocatalytic property was considered to be benefit from the unique hollow microstructure, and the updated $\mathrm{SnO}_{2}$ hollow microspheres were good candidates for synthesis of composite photocatalysts in area of photo degradation, such as $\mathrm{C}_{3} \mathrm{~N}_{4}-\mathrm{SnO}_{2}$, etc.
\end{abstract}

Keywords: $\mathrm{SnO}_{2}$, hollow microsphere, Tetracycline hydrochloride, Photocatalytic degradation

\section{FULL TEXT}

(C) 2020 The Authors. Published by ESG (www.electrochemsci.org). This article is an open access article distributed under the terms and conditions of the Creative Commons Attribution license (http://creativecommons.org/licenses/by/4.0/). 